\title{
Prevalence of Electronic Health Records in U.S. Hospitals
}

\author{
Jean M. Abraham, Ph.D. 1, Jeff S. McCullough, Ph.D. ${ }^{2}$, Stephen T. Parente, \\ Ph.D. ${ }^{3}$, Martin S. Gaynor, Ph.D. ${ }^{4}$ \\ ${ }^{1}$ Division of Health Policy \& Management, School of Public Health, \\ University of Minnesota, Minneapolis, MN USA \\ ${ }^{2}$ Division of Health Policy \& Management, School of Public Health, \\ University of Minnesota, Minneapolis, MN USA \\ ${ }^{3}$ Carlson School of Management, University of Minnesota, Minneapolis, MN USA \\ ${ }^{4}$ H. John Heinz III College, Carnegie Mellon University, Pittsburgh, PA USA
}

Submitted July 2010. Accepted for publication January 2011.

\begin{abstract}
This work provides prevalence estimates for electronic health record (EHR) systems within U.S. hospitals in 2008. Specifically, we identify the set of information technology (IT) applications that provide the technological pre-conditions for hospitals' achievement of meaningful use. We estimate a set of descriptive and multivariate analyses to identify the organizational attributes that are significantly related to EHR adoption. In addition to considering IT applications individually, we consider the cumulative adoption by hospitals. Our results suggest that most U.S. hospitals continue to lack the technological pre-conditions for achieving meaningful use. Approximately $72 \%$ of hospitals had adopted three or fewer of these key applications. Furthermore, we observe some evidence of complementarities between IT and other production inputs. Finally, ownership status, system affiliation, and geographic location are all significantly related to IT adoption. These results provide a useful benchmark for pending IT investments resulting from health reform.
\end{abstract}

Keywords: health information technology, technology adoption, hospital behavior, health reform, health economics

\section{INTRODUCTION}

Health information technology (IT) has the potential to improve quality and reduce costs within health care organizations. Health IT can capture clinical information, provide decision support services, coordinate care, and reduce communication errors

${ }^{1}$ Corresponding author. Email: Jean M. Abraham, Ph.D., Assistant Professor, University of Minnesota, School of Public Health, 420 Delaware Street SE, MMC 729; Minneapolis, MN 55455 USA. Phone: 612-625-4375, Fax: 612-624-2196; E-mail: abrah042@umn.edu. Other authors: mccu0056@umn.edu; sparente@umn.edu; mgaynor@andrew.cmu.edu. 
during handoffs between physicians and other health care providers [1]. Recently, the US federal government allocated approximately $\$ 19$ billion to subsidize the adoption and implementation of health IT.

Within health care settings, IT includes both administrative and clinical functions. Electronic health record (EHR) systems form the foundation for the latter. With a focus on the role of IT for improving patient safety, the Institute of Medicine [2, 3] emphasizes EHR functions that include the capture of health information, management of clinical results, electronic entry of orders for medications and other services, and clinical decision support. They also highlight the ability of health IT to collect clinical data to meet public, private, and institutional reporting requirements.

A comprehensive EHR system is composed of many interoperable IT applications. Basic clinical and patient data are gathered in a clinical data repository (CDR). The CDR compiles data from a wide range of services including laboratory, radiology, and pharmacy. ${ }^{1}$ More sophisticated systems allow providers to access these data using nurse chart and computerized patient record (CPR) applications. Similarly, picture archiving communications systems (PACS) facilitate the distribution and analysis of radiological images. These applications replace traditional paper records as their functionality and penetration improve.

Ideally, providers interact with these records electronically. Clinical data within EHRs may be used by clinical decision support (CDS) applications. These decision support systems may be used to implement a wide range of treatment guidelines, but often they are designed to prevent medication errors. For example, CDS applications may search for drug interactions, drug allergies, or dosage errors [5]. Within advanced systems, orders are made electronically using computerized provider order entry (CPOE), which can reduce communication errors and facilitate real-time decision support [6].

Comprehensive EHRs can further support the filling and dispensing of medication orders. Pharmacy services are facilitated by electronic medication administration records (eMARs). Similarly, nurse chart applications in conjunction with eMARs facilitate the accurate tracking and dispensing of medication orders, thus closing the loop from prescribing to dispensing. Together, these applications provide the technological infrastructure necessary for comprehensive EHRs. Naturally, the value of health IT will depend on its adoption, implementation, and utilization [7].

Overall health IT investment is low in US hospitals and there is extensive variation in IT application prevalence. For example, recent work by Jha et al. [8] estimated that $9.2 \%$ of US hospitals had a basic EHR system and $34 \%$ of hospitals had fully implemented CPOE. The latter is considered by many to be a proxy for EHR adoption within an inpatient setting. Thus, most hospitals still lack the technological

\footnotetext{
${ }^{1}$ For most hospitals, early health IT systems were focused on billing and charge capture capabilities; thus, lab, pharmacy, and radiology management systems diffused rapidly but often lacked clinical functionality. These systems are now nearly universal and are not discussed in this paper. See McCullough [4] for a more detailed discussion of their diffusion.
} 
infrastructure necessary to achieve substantive quality improvement from the utilization of health IT. ${ }^{2}$

Several perceived barriers to health IT adoption exist. One such barrier is financial, since IT systems require large capital investment and maintenance costs, and because providers are uncertain about the value they will derive from systems as measured by return-on-investment [11]. Perceived legal exposure represents a second type of barrier. Medical providers and administrators are concerned about the introduction of new compliance issues related to the Health Insurance Portability and Accountability Act (HIPAA) and greater exposure of information in cases of civil liability litigation. The third type of barrier is technology-related, where hospitals are concerned about the obsolescence of the technology and the decision to adopt IT that does not or will not conform to future standards $[12,13]$.

To encourage broader adoption and use of IT by health care providers, several provisions are included within the American Recovery and Reinvestment Act (ARRA) of 2009, which is federal legislation that included stimulus funds to create jobs and promote investment during the economic recession. One critical objective of this legislation is to create the regulatory infrastructure to develop a set of standards that would help ameliorate existing information technology-related barriers. A second objective is to encourage the adoption and use of IT within hospitals and other health care organizations across the United States.

Meaningful use is defined as an organization using IT to facilitate greater information exchange among health professionals and to make progress toward achieving five broad goals: (a) improving quality, safety, efficiency, and reducing health disparities; (b) engaging patients and families; (c) improving care coordination; (d) ensuring adequate privacy and security protections for personal health information; and (e) improving population and public health (see http://www.himss.org/content/files/ BasicFactsAboutMeaningfulUseARRA.pdf, 2010). Meaningful use cannot, however, be achieved without organizations first meeting the technological pre-conditions, that is, adoption of the IT applications that comprise EHR systems. Our research objective is to provide updated prevalence estimates for EHR systems within US hospitals. Specifically, we focus on the set of IT applications that provide the technological preconditions that would be necessary for hospital organizations to achieve meaningful use. We empirically investigate associations between the adoption of IT systems that comprise an EHR and hospital attributes, including measures of labor and capital inputs, as well as other organizational factors. These relationships provide insights into both adoption costs and production complementarities. In particular, we are interested in understanding whether IT adoption is associated with the use of more labor and capital inputs or fewer.

\footnotetext{
${ }^{2}$ Lower response rates from the American Hospital Association (AHA) IT supplement (63 percent in 2008 and 69 percent in 2009) may create uncertainty regarding whether or not findings from Jha et al. [9] and Jha et. al. [10] are nationally representative. In contrast, the Health Information Management Systems Society (HIMSS) Analytics database covers more than $90 \%$ of all U.S. general, acute care, non-federal hospitals.
} 
We examine hospitals' adoption decisions of individual systems as well as cumulative adoption. The latter is important because while initial health IT applications were often independent, many of these technologies are increasingly used as interoperable systems. Second, the pattern of adoption across applications contains information regarding technological complementarity across applications within a comprehensive information system (See [14] for a historical description of cross application diffusion paths). An ordered framework that captures cumulative adoption decisions can more effectively address these issues.

\subsection{Prior Research}

Research on the adoption of IT in health care settings exists both for organizations in the United States as well as other industrialized nations [15-20]. However, at present, international studies that focus exclusively on hospital-based IT adoption are limited [21]. Exceptions include very recent work focusing on hospitals in Austria and Germany [22], Taiwan [23, 24], and Greece [25].

Within the United States, early work by Parente and Dunbar [26] used a survey of US hospitals receiving Medicare prospective payment to examine the relationship between a hospital's financial performance and its adoption of integrated information systems. In bivariate analyses, they found that hospitals investing in IT had higher total profit margins, but that the relationship disappeared within the multivariate regression specification. Also looking at hospital finances and IT adoption, Borzekowski [27] used panel data and found that although hospital finances were most likely related to IT adoption in the 1970s, this effect had attenuated by the early 1980s.

Burke et al. [28] used the American Hospital Association's (AHA) annual survey of hospitals along with the 1999 Dorenfest/HIMSS (Health Information Management Systems Society) survey of hospital IT adoption. ${ }^{3}$ Using bivariate statistical analyses, they explored organizational differences in hospital adoption of administrative, clinical, and strategic IT systems. They found that hospital size, system membership, and the degree of market concentration are positively related to adoption of all three classes of systems. Using later years of the same data sources, Wang et al. [29] also explored the factors associated with hospitals' adoption of administrative, clinical, and strategicmanagerial systems, focusing on 1,441 urban US hospitals. They found that larger, system-affiliated and for-profit hospitals are more likely to adopt managerial IT, which encompasses applications to analyze finances, allocate resources, and oversee quality improvement operations. They also found statistically significant relationships between IT adoption and operating revenues and between IT adoption and contracts with preferred provider organizations, which are a common form of health plan.

More recent work in this literature has begun to investigate specific IT applications. For example, Cutler et al. [30] examined the effect of a hospital's finances and organizational characteristics on CPOE adoption. Using data from the Leapfrog Group's Hospital Patient Safety Survey, 2000 Medicare Cost Reports, and the 2000

\footnotetext{
${ }^{3}$ See details on these two surveys in the Data and Measures section below.
} 
AHA annual survey, the authors found that government hospitals are more likely to adopt CPOE relative to non-profit organizations, and that for-profit entities are the least likely to adopt. Additionally, they reported that larger hospitals are more likely to have adopted CPOE relative to smaller ones. However, they found no statistically significant relationship between $\mathrm{CPOE}$ adoption and either system affiliation or net income per admission.

Fonkych and Taylor [31] estimated the effect of hospital characteristics on the adoption of CPOE, EMR, and PACS. Using HIMSS data from early 2004, they found that adoption was increasing in both scale and academic status, while it was decreasing in both Medicare and Medicaid admissions. Additionally, they found that for-profit hospitals were considerably less likely to employ clinical IT than non-profit hospitals, but were more likely to invest in managerial-focused IT.

McCullough [32] estimated the hazard of IT adoption as a function of hospital characteristics, market concentration, and adoption behavior of neighboring hospitals using an 11 year panel of hospitals' laboratory, pharmacy, and radiology IT behavior for 1990-2000. While he focused on applications with limited clinical functionality, his findings suggest that competition and strategic behavior had little effect on hospitals' IT adoption decisions. Rather, adoption decisions are largely driven by variation in hospital characteristics and the scalability of IT. Multihospital systems are also more likely to adopt. This may reflect an ability to negotiate better prices or learn from other system-member's adoption.

Furukawa et al. [33] examined the extent of health IT adoption in US hospitals in 2006. In their paper, they explored how hospital characteristics and geographic location relate to the adoption of health IT with particular focus on medication safety. Using the 2006 HIMSS data and AHA annual survey, they examined eight health IT applications that exhibit variation across levels of adoption, impact of safety, and degree of maturity. They estimated multivariate logistic regression to analyze the probability of health IT adoption as well as Poisson regressions to analyze the number of health IT applications adopted per hospital. The authors found that hospital size and ownership are positively related to health IT, with large hospitals (defined as those with 200 or more beds) having 3 to 4 times greater adoption than the smallest hospitals (1-49 beds). Additionally, they reported that non-profit, teaching hospitals, and hospitals with system affiliation have higher rates of adoption relative to for-profit, non-teaching, and independent hospitals, respectively.

Using a supplement to the 2008 AHA's annual survey, Jha et al. [34] investigated the electronic health records functions of 3,049 US hospitals. Hospitals were surveyed about the presence or absence of 32 clinical functionalities of an EHR and whether full implementation had occurred across one or more hospital units. Using the survey results, they concluded that $7.6 \%$ of hospital respondents had a basic system in place in at least one clinical unit, but that only $1.5 \%$ of hospitals had a comprehensive EHR in all units. In a recent follow-up study, Jha et al. [35] updated these results using early 2009 AHA data and reported modest gains. The percentage of hospitals having a basic system increased to $9.2 \%$, while the percentage with a comprehensive system increased to $2.7 \%$. 


\subsection{Objectives}

Health IT is a rapidly evolving field. The adoption and utilization decisions of hospitals are dynamic. This study provides an updated description of health IT adoption for a near census of US hospitals using the 2008 HIMSS Analytics survey. Specifically, we focus on the technological pre-conditions that are necessary for hospitals' achievement of meaningful use, and examine the set of IT applications that cover a continuum of clinical services within hospitals. We quantify associations between IT adoption and hospital attributes, including how adoption relates to other factors of production (labor and capital). Our analyses can provide insights about the complementarities of IT with other inputs, as well as organizational factors that may proxy for adoption preferences. Finally, we examine hospitals' cumulative adoption of IT, which recognizes that individual technologies are increasingly used as interoperable systems.

\section{METHODS}

\subsection{Data and Measures}

We employ two data sources. Our information technology data come from the 2008 Health Information Management Systems Society (HIMSS) Analytics survey (http://www.himssanalytics.org/). The survey is conducted via telephone with repeated follow-ups for completeness. The HIMSS Analytics survey captures approximately 90\% of all acute care, non-federal US hospitals. Once completed, hospital profiles are submitted to interviewees for validation. Finally, HIMSS provides benchmarking reports to respondents as an incentive for accuracy and completeness. These data have been used regularly by IT vendors and employed repeatedly for health services research (e.g., Fonkych and Taylor [36]; Wang et al. [37]; Parente and Van Horn [38]; Furukawa et al. [39]; Parente and McCullough [40]; McCullough et al. [41]).

Our second data source is the 2007 AHA's annual survey, which provides a rich description of hospital characteristics and encompasses nearly all short-term, general hospitals within the United States. For the analysis, we consider several factors. We used staffed hospital beds to capture hospital scale. We incorporated staffed beds and staffed beds squared to allow for a flexible relationship between scale and IT prevalence. We also considered labor inputs, measured as full-time equivalents (FTEs), for registered nurses, laboratory technicians, and licensed pharmacists. To capture teaching hospital status, we defined a binary indicator for whether a hospital has Council of Teaching Hospitals (COTH) membership. Hospitals were further distinguished by ownership (forprofit, government-owned, and not-for-profit status) and system membership. A hospital's payer mix is captured by the percentage of inpatient days covered by Medicare and Medicaid, respectively. Finally, we included a set of indicator variables to capture whether the hospital is located in the major US census regions, Northeast, Midwest, South, or West, as well as a binary indicator for location in a metropolitan statistical area. In merging together the AHA and HIMSS databases, we obtained a final sample which includes 4,381 general, acute care, non-federal, US hospitals - a near census.

Using these data, we estimated the prevalence of seven health IT applications that provide the foundation for a comprehensive EHR system. Three applications form the foundation for the electronic medical record (EMR): a clinical data repository (CDR), 
a computerized patient record (CPR), and clinical decision support systems (CDS) [42]. The CDR gathers and stores data from disparate sources, including lab, pharmacy, and radiology management systems (these applications are nearly ubiquitous by 2008). The CPR organizes these data for use in supplementing or replacing patient records. Finally, CDS applications use these data to support clinical decision making. ${ }^{4}$ Hospitals may also supplement the electronic medical record with nursing documentation (also known as nurse charts). This IT application enables electronic tracking and documentation of nurses' notes regarding the provision of services to patients.

Ideally, physicians and other clinical providers access patients' data electronically via CPOE. When fully implemented, CPOE provides a format for providers to enter orders electronically with the benefit of decision-support algorithms. This technology has the potential to avert both clinical decision and communication errors, particularly for medication orders. Medication orders are transmitted to the pharmacy department where they may be accessed by pharmacy staff. Electronic medication administration record (eMAR) applications track the filling and dispensing of medication orders. The eMAR often works in conjunction with nurse chart applications. The EMR, CPOE, eMAR, and Nurse chart applications help form a closed-loop medication administration system. Finally, PACS facilitate the transmission and evaluation of radiology images. PACS systems also provide widespread access to images and may actually facilitate image reading through software support.

Since health IT applications work in a complementary fashion, we also explored hospitals' cumulative adoption. Our approach for defining adoption phases is based upon prior research that documents diffusion patterns of hospital-based clinical IT systems [43]. We constructed an index describing an ordered sequence, phases, of health IT adoption. However, we recognize the adoption paths across our technology space are not unique. Hospitals reporting no clinical applications are considered to be in phase 1 . Hospitals are considered to be in phase 2 if they report having two of the seven EHR applications and phase 3 if they have at least three applications. Phase 4 hospitals report having limited EMR capability as well as PACS, eMAR, and Nurse Charting. Phase 5 hospitals are those that have CPOE and at least four other applications. Hospitals in phase 6 report having all seven clinical applications.

While clear historical and technological trends in adoption exist (e.g., virtually all EHRs include some CDR functionality), considerable heterogeneity remains across hospitals in the measurement and organization of health IT. For example, some hospitals with otherwise sophisticated health IT systems might not report the presence of a CDR. This most likely reflects measurement error as the CDR features would almost certainly be incorporated into the functionality of other EHR components. Thus, we allowed for some flexibility in our phases and employ a combination of application counts and heuristics. Both the definition and prevalence of these phases are described in Figure 1. We have explored the sensitivity of our results to alternative specifications and found results consistent with those reported below.

\footnotetext{
${ }^{4}$ It is important to note that the HIMSS definition of decision support falls short of "meaningful use" definitions.
} 


\section{Phases of IT Adoption in U.S. Hospitals, 2008}

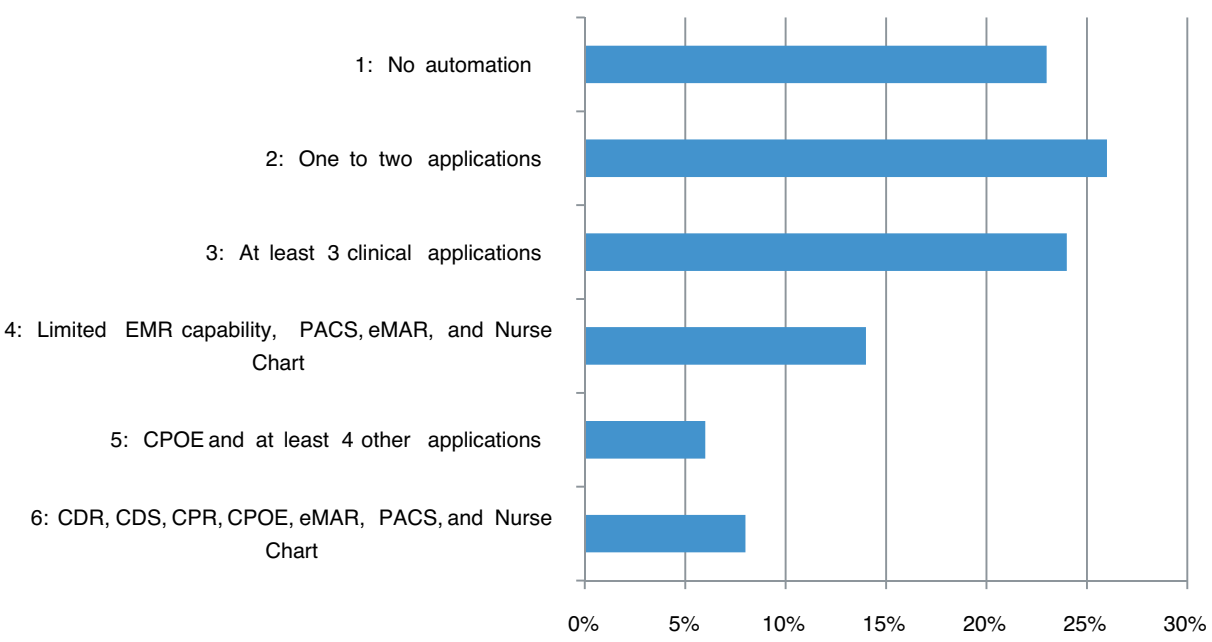

Figure 1. Phases of IT adoption in U.S. hospitals, 2008

\subsection{Analyses}

We conducted bivariate and multivariate analyses to examine the association between hospital characteristics and the adoption of health IT applications. For the bivariate analyses, we tested whether hospitals with or without a particular application differed in their organizational attributes. Formally, we employed a two-population t-test to determine whether means differ significantly. Levels are noted with asterisks $(* * * \mathrm{p}<.01, * * \mathrm{p}<.05, * \mathrm{p}<.10)$.

For the multivariate regression models, we began with a set of binary probit models to estimate the independent relationship between hospital attributes and the probability that an organization reports having a particular IT application. Since health IT systems are comprised of bundles of interoperable applications, we also measure prevalence using the index defined above to measure the phase of adoption. Since our index takes on six values ordered by extent of adoption, we employed an ordered probit to estimate the association between hospital attributes and the phase of IT adoption.

\section{RESULTS}

Table 1 provides variable names, definitions, and descriptive statistics for the IT applications and hospital characteristics. For the three IT applications that comprise an electronic medical record, we find that $74 \%$ of hospitals report having a $\mathrm{CDR}^{5}, 57 \%$ report having a CDS, and $42 \%$ have a CPR. However, only $33 \%$ of hospitals report having all three applications. We also find considerable variability in prevalence rates

\footnotetext{
${ }^{5}$ It is important to note that CPR does not inherently include a database capability, whereas it is meant to identify a long term data repository/re-use function.
} 
Table 1. Variable definitions and descriptive statistics

\begin{tabular}{|c|c|c|c|}
\hline \multirow[b]{2}{*}{ Variables } & \multirow[b]{2}{*}{ Definition } & \multicolumn{2}{|c|}{$\begin{array}{l}\text { Sample of U.S. Hospitals } \\
\qquad(n=4,381)\end{array}$} \\
\hline & & $\begin{array}{l}\text { Mean or } \\
\text { Proportion }\end{array}$ & $\begin{array}{l}\text { Standard } \\
\text { Deviation }\end{array}$ \\
\hline \multicolumn{4}{|c|}{ Dependent variables } \\
\hline $\mathrm{CDR}$ & 1: clinical data repository, 0 otherwise & .74 & - \\
\hline CDS & 1: clinical decision support, 0 otherwise & .57 & - \\
\hline CPR & 1: computerized patient records, 0 otherwise & .42 & - \\
\hline PACS & $\begin{array}{l}\text { 1: picture archiving communications system, } \\
0 \text { otherwise }\end{array}$ & .71 & - \\
\hline eMAR & $\begin{array}{l}\text { 1: electronic medication administration } \\
\text { record, } 0 \text { otherwise }\end{array}$ & .35 & - \\
\hline CPOE & $\begin{array}{l}\text { 1: computerized physician order entry, } \\
0 \text { otherwise }\end{array}$ & .20 & - \\
\hline Nurse Chart & 1: nurse charting system, 0 otherwise & .52 & - \\
\hline \multicolumn{4}{|c|}{ Explanatory variables } \\
\hline $\begin{array}{l}\text { Staffed beds } \\
\text { Registered Nurse } \\
\text { Full-Time } \\
\text { Equivalents } \\
\text { (FTEs) }\end{array}$ & $\begin{array}{l}\text { Number of staffed beds } \\
\text { Number of full-time equivalent } \\
\text { registered nurses }\end{array}$ & $\begin{array}{l}159 \\
254\end{array}$ & $\begin{array}{l}184 \\
368\end{array}$ \\
\hline $\begin{array}{l}\text { Lab technologist } \\
\text { Full-time } \\
\text { equivalents (FTEs) }\end{array}$ & $\begin{array}{l}\text { Number of full-time equivalent laboratory } \\
\text { technicians }\end{array}$ & 19 & 35 \\
\hline $\begin{array}{l}\text { Pharmacist } \\
\text { Full-Time } \\
\text { equivalents } \\
\text { (FTEs) }\end{array}$ & $\begin{array}{l}\text { Number of full-time equivalent licensed } \\
\text { pharmacists }\end{array}$ & 8 & 13 \\
\hline $\begin{array}{l}\text { Proportion days } \\
\text { Medicare }\end{array}$ & $\begin{array}{l}\text { Proportion of inpatient days covered } \\
\text { by Medicare }\end{array}$ & .50 & -- \\
\hline $\begin{array}{l}\text { Proportion days } \\
\text { Medicaid }\end{array}$ & $\begin{array}{l}\text { Proportion of inpatient days covered } \\
\text { by Medicaid }\end{array}$ & .19 & - \\
\hline $\begin{array}{l}\text { Council of } \\
\text { Teaching } \\
\text { Hospitals } \\
\text { Member }\end{array}$ & $\begin{array}{l}\text { 1: if hospital is member of Council of } \\
\text { Teaching Hospitals, } 0 \text { otherwise }\end{array}$ & .06 & - \\
\hline For-profit & $\begin{array}{l}\text { 1: hospital is for-profit ownership status, } \\
0 \text { otherwise }\end{array}$ & .15 & - \\
\hline
\end{tabular}

Table 1. (Continued) 
Table 1. Variable definitions and descriptive statistics (Continued)

\begin{tabular}{|c|c|c|c|}
\hline Variables & Definition & $\begin{array}{l}\text { Mean or } \\
\text { Proportion }\end{array}$ & $\begin{array}{l}\text { Standard } \\
\text { Deviation }\end{array}$ \\
\hline Government & $\begin{array}{l}\text { 1: hospital is government ownership status, } \\
0 \text { otherwise }\end{array}$ & .24 & - \\
\hline $\begin{array}{l}\text { Not-for-profit } \\
\text { hospital }\end{array}$ & $\begin{array}{l}\text { 1: hospital is not-for-profit ownership status, } \\
0 \text { otherwise }\end{array}$ & .61 & - \\
\hline $\begin{array}{l}\text { Multi-hospital } \\
\text { system }\end{array}$ & $\begin{array}{l}\text { 1: hospital is member of a multi-hospital } \\
\text { system }\end{array}$ & .54 & - \\
\hline \multicolumn{4}{|l|}{ Northeast } \\
\hline Census Region & $\begin{array}{l}\text { 1: hospital located in Northeast census region, } \\
0 \text { otherwise }\end{array}$ & .13 & - \\
\hline $\begin{array}{l}\text { Midwest Census } \\
\text { Region }\end{array}$ & $\begin{array}{l}\text { 1: hospital located in Midwest census region, } \\
0 \text { otherwise }\end{array}$ & .30 & - \\
\hline $\begin{array}{l}\text { South Census } \\
\text { Region }\end{array}$ & $\begin{array}{l}\text { 1: hospital located in South census region, } \\
0 \text { otherwise }\end{array}$ & .38 & - \\
\hline $\begin{array}{l}\text { West Census } \\
\text { Region } \\
\text { Metropolitan }\end{array}$ & $\begin{array}{l}\text { 1: hospital located in West census region, } \\
0 \text { otherwise }\end{array}$ & .19 & - \\
\hline Statistical Area & $\begin{array}{l}\text { 1: hospital located in metropolitan statistical } \\
\text { area, } 0 \text { otherwise }\end{array}$ & .56 & - \\
\hline
\end{tabular}

among the other applications. For example, only $20 \%$ of hospitals indicate the presence of a CPOE application as of 2008, while $71 \%$ have adopted the PACS technology.

Table 2 provides bivariate analyses. In particular, we summarize the characteristics of hospitals by whether they have a particular IT application or not. In each case, we test for whether the average value of the hospital attribute differs between adopters and non-adopters. Across the analyses, we observe that adopting facilities are larger, as measured by the number of staffed beds as well as the number of full-time equivalent nurses, laboratory technicians, and pharmacists. We also find that hospitals with IT applications are more likely to be teaching hospitals, have not-for-profit ownership status, and are affiliated with a system.

\subsection{Adoption of Individual IT Applications}

In order to estimate the association between each attribute and the probability that a hospital has adopted a particular clinical IT application, we estimated a set of five binary probit models. Each specification corresponds to whether or not a hospital reports having EMR, CPOE, PACS, eMAR, or Nurse Chart applications. Our results for the binary probit are reported in Table 3 . To facilitate interpretation, marginal effects ${ }^{6}$ and standard errors are reported in lieu of parameter estimates.

${ }^{6}$ The marginal effect can be interpreted as the effect of a one unit change in an independent variable on the probability of adoption. Since probit models are nonlinear, the direct parameter estimates do not measure this effect. 


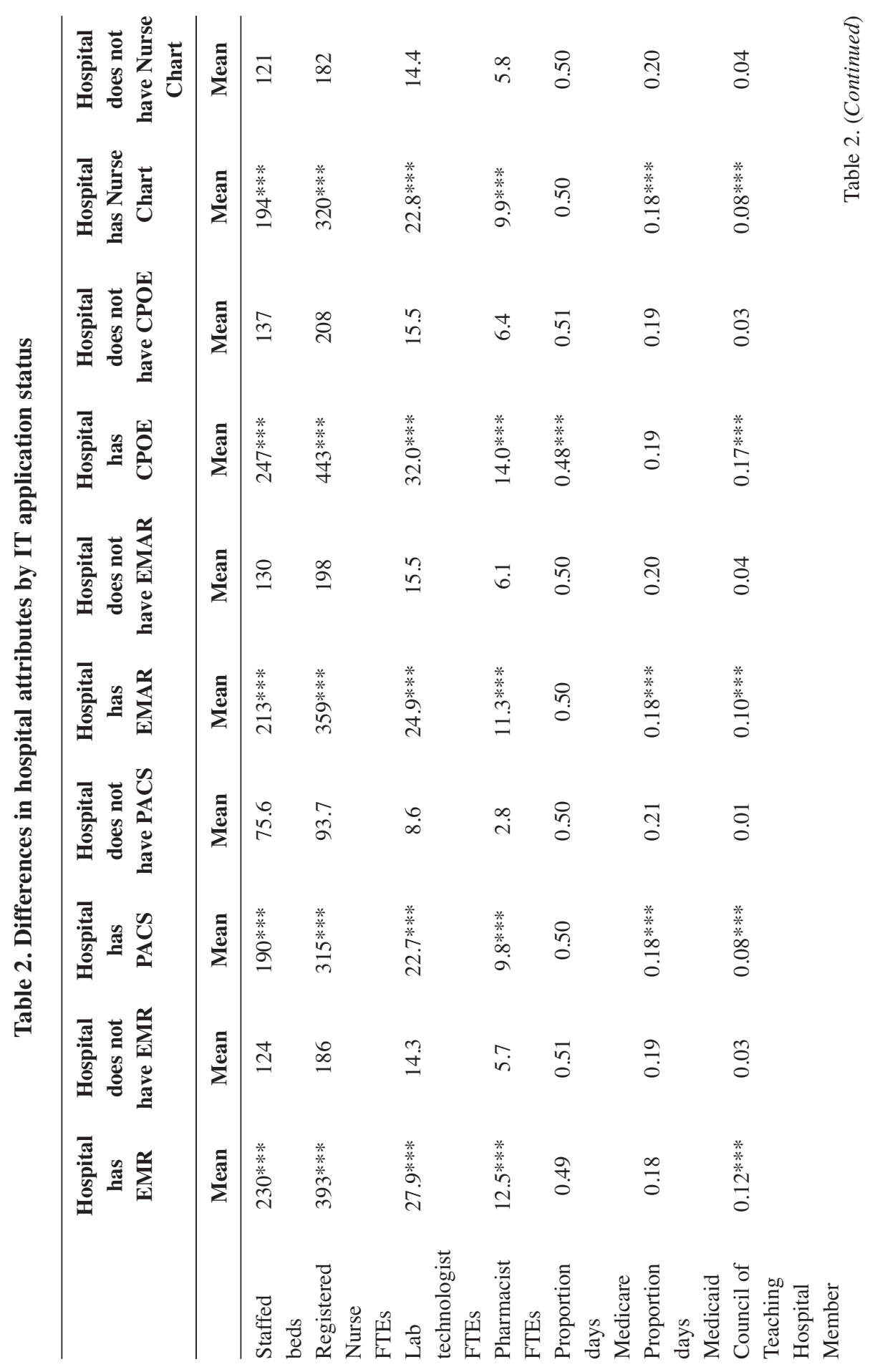




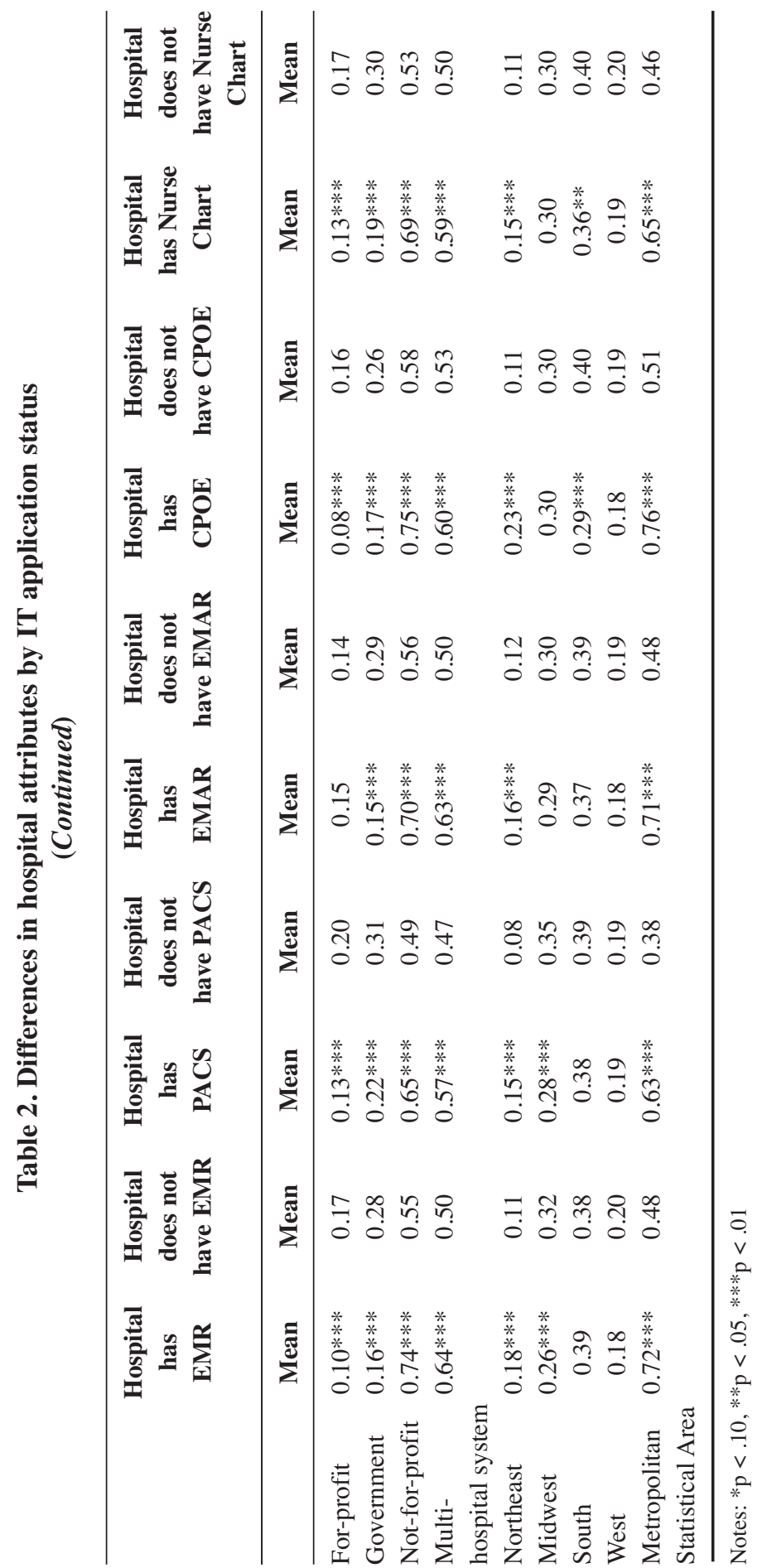


Table 3. Marginal effects of IT hospital characteristics on IT application prevalence, based on multivariate probit models (Marginal effects reported with standard errors in parentheses)

\begin{tabular}{|c|c|c|c|c|c|}
\hline & $\begin{array}{c}\text { (1) } \\
\text { EMR }\end{array}$ & $\begin{array}{c}(2) \\
\text { CPOE }\end{array}$ & $\begin{array}{c}\text { (3) } \\
\text { PACS }\end{array}$ & $\begin{array}{l}\text { (4) } \\
\text { eMAR }\end{array}$ & $\begin{array}{c}\text { (5) } \\
\text { Nursing } \\
\text { Chart }\end{array}$ \\
\hline \multirow{2}{*}{$\begin{array}{l}\text { Beds (measured } \\
\text { in } 100 \mathrm{~s} \text { ) }\end{array}$} & $0.06^{* * *}$ & 0.008 & $0.06^{* * *}$ & $0.05 * * *$ & $0.07 * * *$ \\
\hline & $(0.01)$ & $(0.01)$ & $(0.02)$ & $(0.01)$ & $(0.02)$ \\
\hline \multirow{2}{*}{$\begin{array}{l}\text { Beds-squared } \\
\text { (measured in 100s) }\end{array}$} & $0.00 * * *$ & $-0.002 * *$ & $-0.01 * * *$ & $-0.005 * * *$ & $-0.004 * * *$ \\
\hline & $(0.00)$ & $(0.00)$ & $(0.00)$ & $(0.00)$ & $(0.00)$ \\
\hline $\begin{array}{l}\text { Registered Nurse FTEs } \\
\text { (measured in 100s) }\end{array}$ & $\begin{array}{l}0.004 \\
(0.01)\end{array}$ & $\begin{array}{l}0.01 * * \\
(0.01)\end{array}$ & $\begin{array}{c}0.05 * * * \\
(0.01)\end{array}$ & $\begin{array}{l}0.01 * \\
(0.01)\end{array}$ & $\begin{array}{l}0.010 \\
(0.01)\end{array}$ \\
\hline \multirow{2}{*}{$\begin{array}{l}\text { Lab Full-time FTEs } \\
\text { (measured in 100s) }\end{array}$} & -0.024 & -0.012 & -0.073 & -0.044 & 0.006 \\
\hline & $(0.03)$ & $(0.03)$ & $(0.06)$ & $(0.03)$ & $(0.04)$ \\
\hline \multirow{2}{*}{$\begin{array}{l}\text { Pharmacist FTEs } \\
\text { (measured in } 100 \mathrm{~s} \text { ) }\end{array}$} & $0.23 *$ & -0.009 & $0.61 * * *$ & 0.192 & -0.143 \\
\hline & $(0.13)$ & $(0.10)$ & $(0.21)$ & $(0.13)$ & $(0.15)$ \\
\hline \multirow{2}{*}{$\begin{array}{l}\text { Council of Teaching } \\
\text { Hospital (yes }=1 \text { ) }\end{array}$} & 0.019 & $0.12 * * *$ & -0.064 & -0.060 & -0.040 \\
\hline & $(0.04)$ & $(0.04)$ & $(0.07)$ & $(0.04)$ & $(0.05)$ \\
\hline For-profit $($ yes $=1)$ & $\begin{array}{c}-0.22 * * * \\
(0.02)\end{array}$ & $\begin{array}{c}-0.08 * * * \\
(0.02)\end{array}$ & $\begin{array}{c}-0.15^{* * *} \\
(0.03)\end{array}$ & $\begin{array}{c}-0.06^{* *} \\
(0.03)\end{array}$ & $\begin{array}{c}-0.16^{* * *} \\
(0.03)\end{array}$ \\
\hline Government $($ yes $=1$ ) & $\begin{array}{c}-0.09 * * * \\
(0.02)\end{array}$ & $\begin{array}{l}-0.028 \\
(0.02)\end{array}$ & $\begin{array}{l}-0.007 \\
(0.02)\end{array}$ & $\begin{array}{c}-0.10^{* * *} \\
(0.02)\end{array}$ & $\begin{array}{c}-0.11 * * * \\
(0.02)\end{array}$ \\
\hline \multirow{2}{*}{$\begin{array}{l}\text { Multihospital system } \\
(y e s=1)\end{array}$} & $0.08 * * *$ & 0.024 & 0.024 & $0.04 *$ & 0.020 \\
\hline & $(0.02)$ & $(0.01)$ & $(0.02)$ & $(0.02)$ & $(0.02)$ \\
\hline \multirow{2}{*}{$\begin{array}{l}\text { Proportion Inpatient } \\
\text { Days Medicare } \\
\text { (measured as a \%) }\end{array}$} & -0.001 & $0.00^{*}$ & 0.000 & -0.001 & -0.001 \\
\hline & $(0.00)$ & $(0.00)$ & $(0.00)$ & $(0.00)$ & $(0.00)$ \\
\hline \multirow{2}{*}{$\begin{array}{l}\text { Proportion Inpatient } \\
\text { Days Medicaid } \\
\text { (measured as a \%) }\end{array}$} & -0.001 & -0.001 & $0.00 *$ & $0.00 * *$ & $0.00 * *$ \\
\hline & $(0.00)$ & $(0.00)$ & $(0.00)$ & $(0.00)$ & $(0.00)$ \\
\hline \multirow{2}{*}{$\begin{array}{l}\text { Metropolitan Statistical } \\
\text { Area (yes=1) }\end{array}$} & $0.11 * * *$ & $0.10 * * *$ & 0.023 & $0.09 * * *$ & $0.08 * * *$ \\
\hline & $(0.02)$ & $(0.02)$ & $(0.02)$ & $(0.02)$ & $(0.02)$ \\
\hline
\end{tabular}

Table 3. (Continued) 
Table 3. Marginal effects of IT hospital characteristics on IT application prevalence, based on multivariate probit models (Marginal effects reported with standard errors in parentheses) (Continued)

\begin{tabular}{lccccc}
\hline & $\begin{array}{c}(\mathbf{1}) \\
\text { EMR }\end{array}$ & $\begin{array}{c}(\mathbf{2}) \\
\text { CPOE }\end{array}$ & $\begin{array}{c}(\mathbf{3}) \\
\text { PACS }\end{array}$ & $\begin{array}{c}(\mathbf{4}) \\
\text { eMAR }\end{array}$ & $\begin{array}{c}(\mathbf{5}) \\
\text { Nursing } \\
\text { Chart }\end{array}$ \\
\hline Northeast (yes=1) & -0.012 & $0.13^{* * *}$ & -0.011 & 0.041 & 0.017 \\
& $(0.03)$ & $(0.03)$ & $(0.03)$ & $(0.03)$ & $(0.03)$ \\
West (yes=1) & $-0.08^{* * *}$ & $0.04 * *$ & $-0.05^{* * *}$ & 0.028 & 0.016 \\
& $(0.02)$ & $(0.02)$ & $(0.02)$ & $(0.02)$ & $(0.02)$ \\
Midwest (yes=1) & $-0.05^{* *}$ & 0.017 & 0.006 & -0.018 & 0.018 \\
& $(0.02)$ & $(0.02)$ & $(0.02)$ & $(0.03)$ & $(0.03)$ \\
Log-Likelihood & -1592 & -2004 & -1664 & -2122 & -2269 \\
Likelihood Ratio & 371.12 & 469.32 & 617.04 & 324.11 & .0567 \\
(Chi-square) & & & & & \\
\hline
\end{tabular}

Notes: $* \mathrm{p}<.10 ; * * \mathrm{p}<.05 ; * * * \mathrm{p}<.01$. Sample size $\mathrm{n}=4,381$. Reference categories include not-for-profit hospitals, non-system, non-metropolitan area, and South census region.

First, we consider the relationship between a hospital's probability of adoption and its other main capital input, staffed beds. Adoption of IT systems typically requires large financial investments. Thus, we would expect that larger hospitals may be better able to spread those fixed costs. ${ }^{7}$ We find hospital size to have a small, positive, but diminishing effect on adoption. For example, an increase of 100 staffed beds (one unit increase) results in about a five percentage point increase in the probability of IT adoption for most applications we consider. This finding reflects returns to scale, but also suggests that health IT may not be perfectly scalable. This positive association between hospital size and probability of adoption is consistent with work by Burke et al. [44], Fonkych and Taylor [45], McCullough [46], and Furukawa et al. [47].

Next, we consider the estimated relationship between a hospital's use of labor inputs and its probability of adopting individual IT applications. From Table 3, we observe that the labor input effects are heterogeneous and not robust across applications. We find some positive associations between registered nurses and pharmacists with adoption, but no effects of laboratory technicians. Moreover, the significant correlations we observe do not appear entirely consistent with applications that are relevant to job design. While these labor inputs are plausibly complementary to IT generally, this pattern may illustrate the potential bias from estimating application-level models.

\footnotetext{
${ }^{7}$ We also tried alternative functional forms using the natural $\log$ of beds. It did not affect the sign or magnitude of our results.
} 
Several organizational attributes are associated with a hospital's probability of adopting IT. Across all five applications, for-profit hospitals are less likely to have adopted these clinical systems relative to not-for-profit facilities (the reference category), a finding that is consistent with work by Cutler [48] and Furukawa et al. [49]. For-profit hospitals are about six percentage points less likely to have adopted eMAR and 22 percent less likely to have adopted EMR. Given the cross-application consistency, decreased adoption by for-profit institutions likely reflects either decreased preference for the benefits of health IT (e.g., quality) or a higher cost of capital. ${ }^{8}$ The pattern is somewhat less robust for government facilities, as we find statistically significant differences only for EMR, eMAR, and Nurse Charting systems.

Hospitals that are affiliated with systems are 8 percentage points more likely to have an EMR and 4 percentage points more likely to have an eMAR relative to independent facilities. Interestingly, once we control for size and the other hospital characteristics, teaching hospitals differ from non-teaching hospitals only for CPOE, where they are 12 percentage points more likely to have adopted this application. This is a large effect, given that the baseline prevalence of CPOE is only $20 \%$ across all hospitals.

Finally, our results suggest that the prevalence of IT is considerably higher (about 10 percentage points) within hospitals located in metropolitan statistical areas. However, we find very little systematic patterns across the four census regions, once we control for urban-rural differences.

\subsection{Cumulative Adoption}

In addition to examining the factors associated with a hospital's use of individual IT applications, we are also interested in understanding cumulative adoption. Figure 1 provides specific criteria used for defining each phase as well as the percentage of US hospitals at each phase. We see that $72 \%$ of hospitals have automated three or fewer of our studied applications. Essentially, most organizations have minimally functional EHRs while only $8 \%$ of hospitals report the presence of all studied applications (Phase 6). Even if we relax our definition of EHR pre-conditions (Phase 5), we see that only $14 \%$ of hospitals possess the technological infrastructure that would be needed to attain meaningful use status.

Using the six phases defined above, we estimated an ordered probit model to identify the set of hospital attributes that are significantly associated with each phase of IT utilization. Again, to facilitate interpretation, we report marginal effects and standard errors in Table 4. Note that for ordered probit models, we report a set of marginal effects for each phase category. The model is also estimated with a reference outcome category (phase 1 in our specification).

As with the individual application models, we continue to find a strong and positive relationship between staffed beds and the cumulative adoption of IT, although the

\footnotetext{
${ }^{8}$ In the United States, not-for-profit hospitals are subsidized through the tax code. The interest earned by investors from not-for-profit hospitals is not subject to corporate taxes. However, not-for-profit hospitals cannot access equity capital markets (e.g., raise money by issuing stock). Consequently, hospital governance affects the cost of capital and may indirectly affect the cost of IT adoption.
} 
Table 4. Ordered probit of phases of IT utilization (Marginal effects reported with standard errors in parentheses)

\begin{tabular}{|c|c|c|c|c|c|}
\hline Explanatory Variables & Phase 2 & Phase 3 & Phase 4 & Phase 5 & Phase 6 \\
\hline Beds (measured in 100s) & $\begin{array}{c}-0.03 * * * \\
(0.00)\end{array}$ & $\begin{array}{c}0.01 * * * \\
(0.00)\end{array}$ & $\begin{array}{c}0.03 * * * \\
(0.00)\end{array}$ & $\begin{array}{c}0.02 * * * \\
(0.00)\end{array}$ & $\begin{array}{c}0.03 * * * \\
(0.00)\end{array}$ \\
\hline $\begin{array}{l}\text { Beds squared } \\
\text { (measured in 100s) }\end{array}$ & $0.002 * * *$ & $\begin{array}{c}-0.001 * * * \\
(0.00)\end{array}$ & $\begin{array}{c}-0.002 * * * \\
(0.00)\end{array}$ & $\begin{array}{c}-0.001 * * * \\
(0.00)\end{array}$ & $\begin{array}{c}-0.002 * * * \\
(0.00)\end{array}$ \\
\hline $\begin{array}{l}\text { Registered Nurse FTEs } \\
\text { (measured in 100s) }\end{array}$ & $\begin{array}{c}-0.01 * * \\
(0.00)\end{array}$ & $\begin{array}{c}0.003 * * \\
(0.00)\end{array}$ & $\begin{array}{l}0.01 * * \\
(0.00)\end{array}$ & $\begin{array}{c}0.003 * * \\
(0.00)\end{array}$ & $\begin{array}{c}0.005^{* *} \\
(0.00)\end{array}$ \\
\hline $\begin{array}{l}\text { Lab Technologists FTEs } \\
\text { (measured in 100s) }\end{array}$ & $\begin{array}{l}0.015 \\
(0.01)\end{array}$ & $\begin{array}{l}-0.007 \\
(0.01)\end{array}$ & $\begin{array}{l}-0.014 \\
(0.01)\end{array}$ & $\begin{array}{l}-0.008 \\
(0.01)\end{array}$ & $\begin{array}{l}-0.013 \\
(0.01)\end{array}$ \\
\hline $\begin{array}{l}\text { Pharmacists FTEs } \\
\text { (measured in 100s) }\end{array}$ & $\begin{array}{l}-0.065 \\
(0.04)\end{array}$ & $\begin{array}{l}0.030 \\
(0.02)\end{array}$ & $\begin{array}{l}0.062 \\
(0.04)\end{array}$ & $\begin{array}{l}0.035 \\
(0.02)\end{array}$ & $\begin{array}{l}0.057 \\
(0.04)\end{array}$ \\
\hline Teaching $(1=$ yes $)$ & $\begin{array}{l}-0.002 \\
(0.01)\end{array}$ & $\begin{array}{l}0.001 \\
(0.01)\end{array}$ & $\begin{array}{l}0.002 \\
(0.01)\end{array}$ & $\begin{array}{l}0.001 \\
(0.01)\end{array}$ & $\begin{array}{l}0.002 \\
(0.01)\end{array}$ \\
\hline For-profit ( $1=$ yes) & $\begin{array}{c}0.04 * * * \\
(0.00)\end{array}$ & $\begin{array}{c}-0.04 * * * \\
(0.01)\end{array}$ & $\begin{array}{c}-0.06 * * * \\
(0.01)\end{array}$ & $\begin{array}{c}-0.03 * * * \\
(0.00)\end{array}$ & $\begin{array}{c}-0.04 * * * \\
(0.00)\end{array}$ \\
\hline Government (1=yes) & $\begin{array}{c}0.04 * * * \\
(0.01)\end{array}$ & $\begin{array}{c}-0.03 * * * \\
(0.01)\end{array}$ & $\begin{array}{c}-0.04 * * * \\
(0.01)\end{array}$ & $\begin{array}{c}-0.02 * * * \\
(0.00)\end{array}$ & $\begin{array}{c}-0.03 * * * \\
(0.00)\end{array}$ \\
\hline $\begin{array}{l}\text { Multihospital system } \\
(1=\text { yes) }\end{array}$ & $\begin{array}{c}-0.02 * * * \\
(0.01)\end{array}$ & $\begin{array}{c}0.01 * * * \\
(0.00)\end{array}$ & $\begin{array}{c}0.02 * * * \\
(0.01)\end{array}$ & $\begin{array}{c}0.01 * * * \\
(0.00)\end{array}$ & $\begin{array}{c}0.02 * * * \\
(0.00)\end{array}$ \\
\hline $\begin{array}{l}\text { Proportion of inpatient } \\
\text { days Medicare } \\
\text { (measured as a \%) }\end{array}$ & 0.000 & 0.000 & 0.000 & 0.000 & 0.000 \\
\hline $\begin{array}{l}\text { Proportion of inpatient } \\
\text { days Medicaid } \\
\text { (measured as a \%) }\end{array}$ & $\begin{array}{c}(0.00) \\
0.0005^{* *}\end{array}$ & $\begin{array}{c}(0.00) \\
-0.0002 * *\end{array}$ & $\begin{array}{c}(0.00) \\
-0.0005 * *\end{array}$ & $\begin{array}{c}(0.00) \\
-0.0003 * *\end{array}$ & $\begin{array}{c}(0.00) \\
-0.0004 * *\end{array}$ \\
\hline $\begin{array}{l}\text { Metropolitan Statistical } \\
\text { Area (1=yes) }\end{array}$ & $\begin{array}{c}(0.00) \\
-0.04 * * *\end{array}$ & $\begin{array}{c}(0.00) \\
0.02 * * *\end{array}$ & $\begin{array}{c}(0.00) \\
0.04 * * *\end{array}$ & $\begin{array}{c}(0.00) \\
0.02 * * *\end{array}$ & $\begin{array}{c}(0.00) \\
0.04 * * *\end{array}$ \\
\hline Northeast ( $1=$ yes $)$ & $\begin{array}{c}(0.01) \\
-0.02 * * \\
(0.01)\end{array}$ & $\begin{array}{l}(0.00) \\
0.01 * * * \\
(0.00)\end{array}$ & $\begin{array}{l}(0.01) \\
0.02 * * \\
(0.01)\end{array}$ & $\begin{array}{c}(0.00) \\
0.01 * * \\
(0.00)\end{array}$ & $\begin{array}{c}(0.01) \\
0.02 * * \\
(0.01)\end{array}$ \\
\hline
\end{tabular}

Table 4. (Continued) 
Table 4. Ordered probit of phases of IT utilization (Marginal effects reported with standard errors in parentheses)

(Continued)

\begin{tabular}{lccccc}
\hline & Phase 2 & Phase 3 & Phase 4 & Phase 5 & Phase 6 \\
\hline Midwest (1=yes) & 0.001 & 0.000 & -0.001 & 0.000 & 0.000 \\
\multirow{2}{*}{ West $(1=$ yes $)$} & $(0.01)$ & $(0.00)$ & $(0.01)$ & $(0.00)$ & $(0.01)$ \\
& 0.006 & -0.003 & -0.006 & -0.003 & -0.005 \\
& $(0.01)$ & $(0.00)$ & $(0.01)$ & $(0.00)$ & $(0.01)$ \\
\hline
\end{tabular}

Note: Phase 1 is the reference outcome. Explanatory reference categories include not-for-profit hospitals, non-system, non-metropolitan area, and South census region. The log-likelihood is -5442 and the likelihood ratio (chi-square) is 875.39 .

magnitudes appear slightly smaller. We observe that larger hospitals are less likely to have Phase 2 adoption - approximately 3 percentage points less likely for each 100 staffed inpatient beds. Conversely, larger hospitals are more likely to achieve Phases 3 through 6 . For each 100 beds, they are 1 percentage point more likely to achieve Phase 3 and about 3 percentage points more likely to achieve Phases 4 and 5. While all effects are significantly different from zero, they are also significantly different from adjacent categories with the exception of Phases 4 and 5. This positive scale effect is moderated by the Beds squared measure. All else equal, a two-hundred bed hospital is more likely to adopt than a one-hundred bed hospital, but the marginal effect of scale is almost zero for 500- or 600-bed institutions.

With respect to the labor inputs, we observe small but persistent effects of registered nurse full-time equivalents (RN FTEs) on hospitals' IT adoption phases. For example, increasing the number of RN FTEs by .1 units (10 RN FTEs) is associated with a .001 increase in the probability that a hospital is in phase 3 . Subsequent examination of whether the magnitudes differ across adjacent categories reveals that the marginal effects for phases 3, 4, and 5 are not different from one another. The pattern of results that we observe for this variable is consistent with complementarities in production of hospital services, rather than substitution away from nurses as additional IT systems are adopted. Among the other labor inputs we find that the pharmacist FTE effects are diminished in the cumulative adoption model and we continue to observe no statistically significant relationship between the lab technician input and IT adoption.

Hospitals that are affiliated with systems also tend to have stronger cumulative adoption, suggesting either decreased costs of capital or learning spillovers, a finding consistent with McCullough [50] and Wang et al. [51]. For this variable, the magnitudes of the effects across adjacent phases are all significantly different from one another, although the magnitudes are quite similar across Phases 3 through 6. Differences by ownership status also persist, with for-profit and government hospitals being less likely to achieve more advanced phases of clinical IT adoption relative to not-for-profit 
facilities. For example, for-profit hospitals are between 3 and 6 percentage points less likely to achieve Phases 3 to 6 , relative to non-profit hospitals. In contrast, teaching hospital status does not exhibit any statistically significant relationship to a hospital's probability of being in a more advanced phase once other controls are included.

In the cumulative adoption model, we observe a consistent, albeit very small, negative relationship between the percentage of inpatient days paid by Medicaid and a hospital's phase of IT utilization. Moreover, we find that the magnitude of this effect is not significantly different for Phases 3, 4, and 5. This result is not too surprising since hospitals that serve a larger percentage of Medicaid patients (as compared to privately insured and Medicare patients) may be more resource-constrained and lack the financial capital for IT investment. Fonkych and Taylor [52] reported a similar relationship. Finally, we observe positive and significant effects for our metropolitan statistical area dummy, suggesting that urban hospitals tend to be much further along in terms of overall IT adoption relative to hospitals located in more rural areas.

\section{DISCUSSION}

This paper has four key findings. First, we find that most US hospitals continue to lack the technological pre-conditions that would be necessary for achieving meaningful use. As of 2008, approximately $72 \%$ of hospitals had adopted three or fewer of these key applications. Second, we observe considerable variation across hospitals with respect to the number and types of IT applications adopted. While PACS, CDR, and Nurse Charting applications are relatively prevalent, most hospitals lack CPOE, CDS, and CPR applications. The relative rates of IT adoption across systems observed in the HIMSS Analytics survey appear qualitatively similar to those reported using alternative sources, although a direct comparison is not feasible, given differences in measurement $[53,54]$.

Third, our results provide insights into the relationship between a hospital's IT adoption decisions and other factors of production, including clinical labor inputs and beds. Our results suggest complementarities between IT adoption and beds. We also find evidence of a positive relationship between phase of IT adoption and registered nurses, a finding that aligns with recent work by Furukawa et al. [55]. They examined hospitals in California between1998 and 2007 and found a positive relationship between EMR implementation and registered nurse staffing levels.

Fourth, we find statistically significant associations between several other organizational attributes and a hospital's probability of IT adoption. Differences are particularly pronounced for small and rural hospitals. Non-profit hospitals also exhibit higher adoption rates relative to for-profit and government hospitals, a finding consistent with prior research [56-59]. While we find that academic hospitals are more likely to adopt IT, this effect is only statistically significant for CPOE. For many of our variables, we observed a similar pattern of relationships when modeling cumulative adoption.

This study faces three notable limitations. First, this study is cross-sectional and empirical relationships may be associative rather than causal. Second, since our measures reflect a single snapshot in time, we are not able to fully capture the evolving 
relationships between hospital characteristics and technology adoption decisions. Ultimately, adoption models should incorporate panel data to formally test for changes in adoption patterns across hospitals over time and whether relationships between organizational attributes and adoption are time-varying. Third, our IT application measures, which are binary in nature, may fail to capture the full complexity underlying health IT adoption and its subsequent implementation.

The passage of ARRA in 2009 is a "game changer" for hospitals as they consider decisions about IT investments. Creation of uniform standards under ARRA should reduce perceived barriers to adoption. In addition, ARRA provisions will create stronger financial incentives for hospitals to invest in and meaningfully use comprehensive hospital EHR systems. Most likely, ARRA will get hospitals beyond just 'beachhead health IT', where the modal hospital has at least two applications. However, to conform to the meaningful use standard and receive the financial incentives from ARRA, hospitals will need to begin by adopting the IT systems necessary to have a functioning EHR. Adoption may also be affected by the diffusion of Accountable Care Organizations, which align providers across the continuum of care as well as other health care reform initiatives. Ultimately, full implementation may facilitate organizational changes, quality reporting, and pay-for-performance initiatives.

\section{CONCLUSIONS}

This paper provides updated national estimates of clinical IT prevalence among shortterm, non-federal, general hospitals in the United States. Our findings indicate that most hospitals have not met the technological pre-conditions that will be necessary for achieving meaningful use. The ongoing monitoring of health IT adoption will be crucial to the discussion and development of health IT policy. With this information, policymakers will have a clearer understanding of the IT infrastructure and the extent to which hospital behavior regarding IT investments will need to change in order to progress toward meeting meaningful use requirements specified in federal legislation.

\section{ACKNOWLEDGEMENT}

The authors thank the Agency of Healthcare Research and Quality (AHRQ) and the Robert Wood Johnson Foundation's Changes in Health Care Financing and Organization (HCFO) program for funding this research and HIMSS Analytics for use of their data.

\section{REFERENCES}

[1] Chaudhry, B. et al. "Systematic Review: Impact of Health Information Technology on Quality, Efficiency, and Costs of Medical Care," Annals of Internal Medicine, 2006, 144(10): 742-752.

[2] Institute of Medicine, Committee on Quality of Health Care in America. Crossing the Quality Chasm: A New Health System for the $21^{\text {st }}$ Century. Washington, DC: National Academy Press; 2001.

[3] Institute of Medicine. Key Capabilities of an Electronic Health Record System: Letter Report. Washington, DC: National Academy Press; 2003.

[4] McCullough, J. "The Adoption of Hospital Information Systems." Health Economics, 2007, 17(5): 649-664. 
[5] Garg, A., N. Adhikari, H. McDonald, M. Rosas-Arellano, P.J. Devereaux, J. Beyene, J. Sam, and R. Haynes. "Effects of Computerized Clinical Decision Support Systems on Practitioner Performance and Patient Outcomes - A Systematic Review.” JAMA March 9, 2005, 293(10): 1223-1238.

[6] Kuperman, G., R. Gibson. "Computer Physician Order Entry: Benefits, Costs, and Issues.” Annals of Internal Medicine, 2003, 139(1): 31-39.

[7] Chaudhry, B. et al. "Systematic Review: Impact of Health Information Technology on Quality, Efficiency, and Costs of Medical Care," Annals of Internal Medicine, 2006, 144(10): 742-752.

[8] Jha, Ashish, C. DesRoches, P. Kralovec, and M. Joshi. "A Progress Report on Electronic Health Records in U.S. Hospitals." Health Affairs, October 2010, 29(10): 1-7.

[9] Jha, Ashish, C. DesRoches, E. Campbell, K. Donelan, S. Rao, T. Ferris, A. Shields, S. Rosenbaum, and D. Blumenthal. "Use of Electronic Health Records in U.S. Hospitals." New England Journal of Medicine, April 16, 2009, 360(16): 1628-1638.

[10] Jha, Ashish, C. DesRoches, P. Kralovec, and M. Joshi. "A Progress Report on Electronic Health Records in U.S. Hospitals." Health Affairs, October 2010, 29(10): 1-7.

[11] Poon, E., D. Blumental, T. Jaggi, M. Honour, D. Bates, and R. Kaushal. "Overcoming Barriers to Adopting and Implementing Computerized Physician Order Entry Systems in U.S. Hospitals," Health Affairs, 2004, 23(4): 184-190.

[12] Jha, Ashish, C. DesRoches, E. Campbell, K. Donelan, S. Rao, T. Ferris, A. Shields, S. Rosenbaum, and D. Blumenthal. "Use of Electronic Health Records in U.S. Hospitals." New England Journal of Medicine, April 16, 2009, 360(16): 1628-1638.

[13] Blumenthal, David, C. DesRoches, K. Donelan, et al. "Health Information Technology in the United States, the Information Base for Progress. Princeton, NJ: Robert Wood Johnson Foundation, 2006.

[14] Fonkych, Kateryna and R. Taylor. "The State and Pattern of Health Information Technology Adoption." RAND Health Report. http://www.rand.org/pubs/monographs/2005/ RAND_MG409.pdf, Accessed May 29, 2010.

[15] Anderson, G, B., Frogner, R. Johns, U. Reinhardt. "Health Care Spending and the Use of Information Technology in OECD Countries." Health Affairs, 2006, 25(3): 819-831.

[16] Didem, R., I. Martin, R. Wood, K. Harrison. "Information Technology Systems in General Practice Medicine in New Zealand.” New Zealand Medicine Journal, 2004 117(1198).

[17] Bywater, M. "UK Findings from HINE European Hospital Survey," Harrogate, England, 2005.

[18] Ausford, A. N. Campbell, D. Gaudette, J. MacGregor. "Implementing an EHR: is it Possible to Sustain the Momentum? E Health 2005 Conference, Toronto, Canada, 2005.

[19] Nohr , C., S. Andersen, S. Vigtoft, K. Bernstein, M. Bruun-Rasmussen. "Development, Implementation, and Diffusion of EHR Systems in Denmark." International Journal of Medical Informatics, 2005, 74(2-4): 229-234.

[20] Yoshishara, H. "Development of the Electronic Health Record in Japan." International Journal of Medical Informatics, 1998, 49(1): 53-58.

[21] Jha, Ashish, D. Doolan, D. Grandt, T. Scott, and D. Bates. "The Use of Health Information Technology in Seven Nations." International Journal of Medical Informatics. 2008, 77(12): 848-854.

[22] Hubner, Ursula, Ammenwerth, E., Flemming, D., Schaubmayr, C., and Sellemann, B. "IT Adoption of Clinical Information Systems in Austrian and German Hospitals: Results of a Comparative Survey with Focus on Nursing." BMC Medical Informatics and Decision Making. 2010, 10(8).

[23] Hung, S., Chen, C. and Lee, W. "Moving Hospitals Toward e-learning Adoption: an Empirical Investigation.” Journal of Organizational Change Management. 2009, 22(3): 239-256.

[24] Hung, S., Hung, W., Tsai, C. and Jiang, S. "Critical Factors of Hospital Adoption on CRM System: Organizational and Information System Perspectives." Decision Support Systems 2010, 48(4): 592-603.

[25] Kitsiou, S.,Manthou, V., Vlachopoulou, M., and Markos, A. “Adoption and Sophistication of Clinical Information Systems in Greek Public Hospitals: Results from a National Web-based Survey." MEDICON 2010 IFMBE Proceedings 29: 1011-1016. 
[26] Parente, S.T. and Dunbar, J. "Is Information Technology Related to the Financial Performance of U.S. Hospitals? An Exploratory Analysis." International Journal of Healthcare Technology and Management., 2001. 3(1): 48-58.

[27] Borzekowski, R. "Health Care Finance and the Early Adoption of Hospital Information Systems." Federal Employment Data System, Working Paper No. 2002-41, LRP Publications. September 2002

[28] Burke, D.E., B. Wang, T. Wan, M. Diana. "Exploring Hospitals' Adoption of Information Technology." 2002, Journal of Medical Systems 26(4): 349-355.

[29] Wang, Bill, B. Wan, D. Burke, G. Bazzoli, and B. Lin. "Factors Influencing Health Information System Adoption in American Hospitals." Health Care Management Review, 2005, 30(1): 44-51.

[30] Cutler, D., N. Feldman, and J. Horwitz. "U.S. Adoption of CPOE Systems." Health Affairs, 2005, 24(6): 1654-1663.

[31] Fonkych, Kateryna and R. Taylor. "The State and Pattern of Health Information Technology Adoption.” RAND Health Report. http://www.rand.org/pubs/monographs/2005/ RAND_MG409.pdf, Accessed May 29, 2010.

[32] McCullough, J. "The Adoption of Hospital Information Systems." Health Economics, 2007, 17(5): 649-664.

[33] Furukawa, Michael, T. Raghu, T. Spaulding, and A. Vinze. "Adoption of Health Information Technology For Medication Safety in U.S. Hospitals, 2006." Health Affairs, 2008, 27(3): 865-875.

[34] Jha, Ashish, C. DesRoches, E. Campbell, K. Donelan, S. Rao, T. Ferris, A. Shields, S. Rosenbaum, and D. Blumenthal. "Use of Electronic Health Records in U.S. Hospitals." New England Journal of Medicine, April 16, 2009, 360(16): 1628-1638.

[35] Jha, Ashish, C. DesRoches, P. Kralovec, and M. Joshi. "A Progress Report on Electronic Health Records in U.S. Hospitals." Health Affairs, October 2010, 29(10): 1-7.

[36] Fonkych, Kateryna and R. Taylor. "The State and Pattern of Health Information Technology Adoption.” RAND Health Report. http://www.rand.org/pubs/monographs/2005/ RAND_MG409.pdf, Accessed May 29, 2010.

[37] Wang, Bill, B. Wan, D. Burke, G. Bazzoli, and B. Lin. "Factors Influencing Health Information System Adoption in American Hospitals." Health Care Management Review, 2005, 30(1): 44-51.

[38] Parente, Stephen T. and R.L. Van Horn. "The Value of Hospital Information Technology in For-Profit and Not-for-Profit Hospitals." Health Care Financing Review, Winter 2006/2007, 28(2): 31-44.

[39] Furukawa, Michael, T. Raghu, T. Spaulding, and A. Vinze. "Adoption of Health Information Technology For Medication Safety in U.S. Hospitals, 2006." Health Affairs, 2008, 27(3): 865-875.

[40] Parente, S.T., McCullough, J. "Health Information Technology and Patient Safety: Evidence from Panel Data." Health Affairs, March/April, 2009, 28(2): 357-360

[41] McCullough, J., Casey, M., Moscovice, I. and S. Prasad. "The Effect of Health Information Technology on Quality In U.S. Hospitals." Health Affairs, April 2010, 29(4): 647-654.

[42] Fonkych, Kateryna and R. Taylor. "The State and Pattern of Health Information Technology Adoption.” RAND Health Report. http://www.rand.org/pubs/monographs/2005/ RAND_MG409.pdf, Accessed May 29, 2010.

[43] Fonkych, Kateryna and R. Taylor. "The State and Pattern of Health Information Technology Adoption.” RAND Health Report. http://www.rand.org/pubs/monographs/2005/ RAND_MG409.pdf, Accessed May 29, 2010.

[44] Burke, D.E., B. Wang, T. Wan, M. Diana. "Exploring Hospitals’ Adoption of Information Technology." Journal of Medical Systems, 2002, 26(4): 349-355.

[45] Fonkych, Kateryna and R. Taylor. "The State and Pattern of Health Information Technology Adoption.” RAND Health Report. http://www.rand.org/pubs/monographs/2005/ RAND_MG409.pdf, Accessed May 29, 2010.

[46] McCullough, J. "The Adoption of Hospital Information Systems." Health Economics, 2007, 17(5): 649-664. 
[47] Furukawa, Michael, T. Raghu, T. Spaulding, and A. Vinze. "Adoption of Health Information Technology For Medication Safety in U.S. Hospitals, 2006.” Health Affairs, 2008, 27(3): 865-875.

[48] Cutler, D., N. Feldman, and J. Horwitz. "U.S. Adoption of CPOE Systems." Health Affairs, 2005, 24(6): 1654-1663.

[49] Furukawa, Michael, T. Raghu, T. Spaulding, and A. Vinze. "Adoption of Health Information Technology For Medication Safety in U.S. Hospitals, 2006." Health Affairs, 2008, 27(3): 865-875.

[50] McCullough, J. "The Adoption of Hospital Information Systems." Health Economics, 2007, 17(5): 649-664.

[51] Wang, Bill, B. Wan, D. Burke, G. Bazzoli, and B. Lin. "Factors Influencing Health Information System Adoption in American Hospitals." Health Care Management Review, 2005, 30(1): 44-51.

[52] Fonkych, Kateryna and R. Taylor. "The State and Pattern of Health Information Technology Adoption.” RAND Health Report. http://www.rand.org/pubs/monographs/2005/ RAND_MG409.pdf, Accessed May 29, 2010.

[53] Jha, Ashish, C. DesRoches, E. Campbell, K. Donelan, S. Rao, T. Ferris, A. Shields, S. Rosenbaum, and D. Blumenthal. "Use of Electronic Health Records in U.S. Hospitals." New England Journal of Medicine, April 16, 2009, 360(16): 1628-1638.

[54] Jha, Ashish, C. DesRoches, P. Kralovec, and M. Joshi. "A Progress Report on Electronic Health Records in U.S. Hospitals.” Health Affairs, October 2010, 29(10): 1-7.

[55] Furukawa, Michael, T. Raghu, B. Shao. "Electronic Medical Records, Nurse Staffing, and NurseSensitive Patient Outcomes: Evidence from California Hospitals, 1998-2007. Health Services Research, 2010, 45(4):: 941-962.

[56] Furukawa, Michael, T. Raghu, T. Spaulding, and A. Vinze. "Adoption of Health Information Technology For Medication Safety in U.S. Hospitals, 2006.” Health Affairs, 2008, 27(3): 865-875.

[57] Fonkych, Kateryna and R. Taylor. "The State and Pattern of Health Information Technology Adoption.” RAND Health Report. http://www.rand.org/pubs/monographs/2005/ RAND_MG409.pdf, Accessed May 29, 2010.

[58] Wang, Bill, B. Wan, D. Burke, G. Bazzoli, and B. Lin. "Factors Influencing Health Information System Adoption in American Hospitals." Health Care Management Review, 2005, 30(1): 44-51.

[59] Jha, Ashish, C. DesRoches, E. Campbell, K. Donelan, S. Rao, T. Ferris, A. Shields, S. Rosenbaum, and D. Blumenthal. "Use of Electronic Health Records in U.S. Hospitals." New England Journal of Medicine, April 16, 2009, 360(16): 1628-1638. 


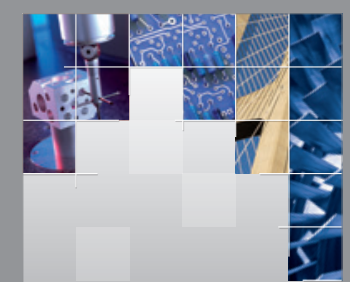

\section{Enfincering}
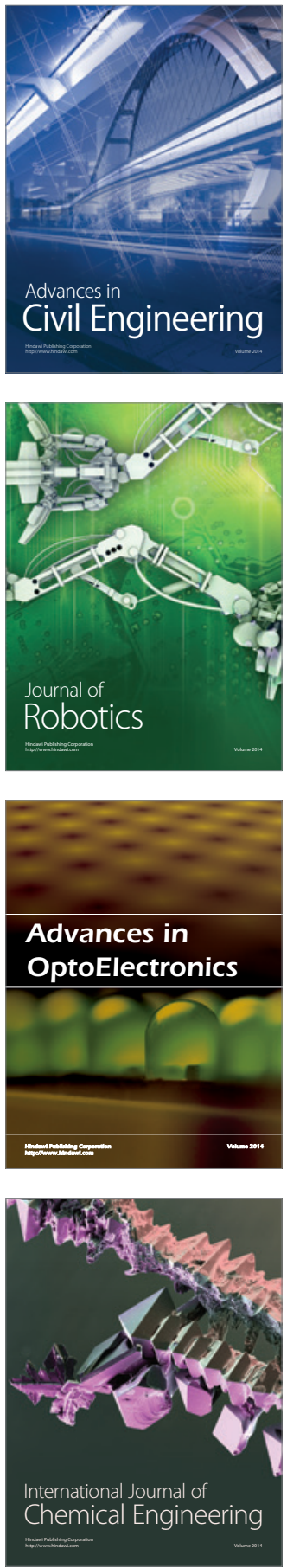

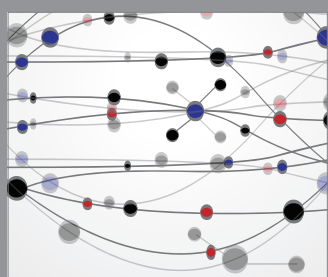

The Scientific World Journal

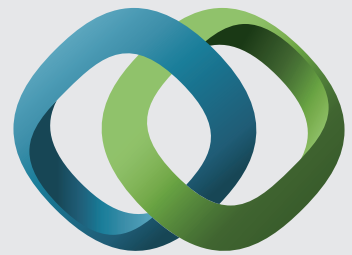

\section{Hindawi}

Submit your manuscripts at

http://www.hindawi.com
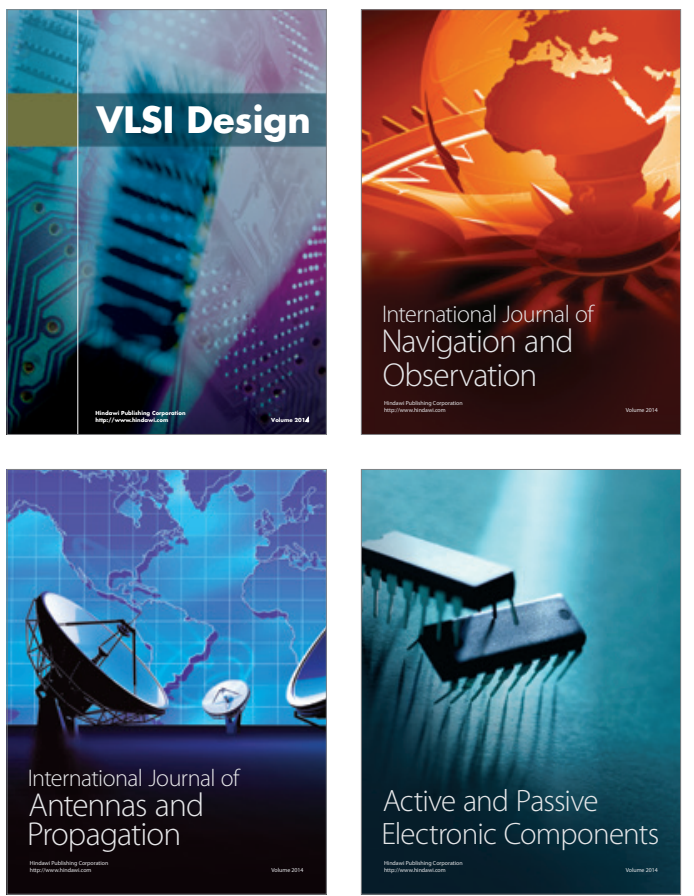
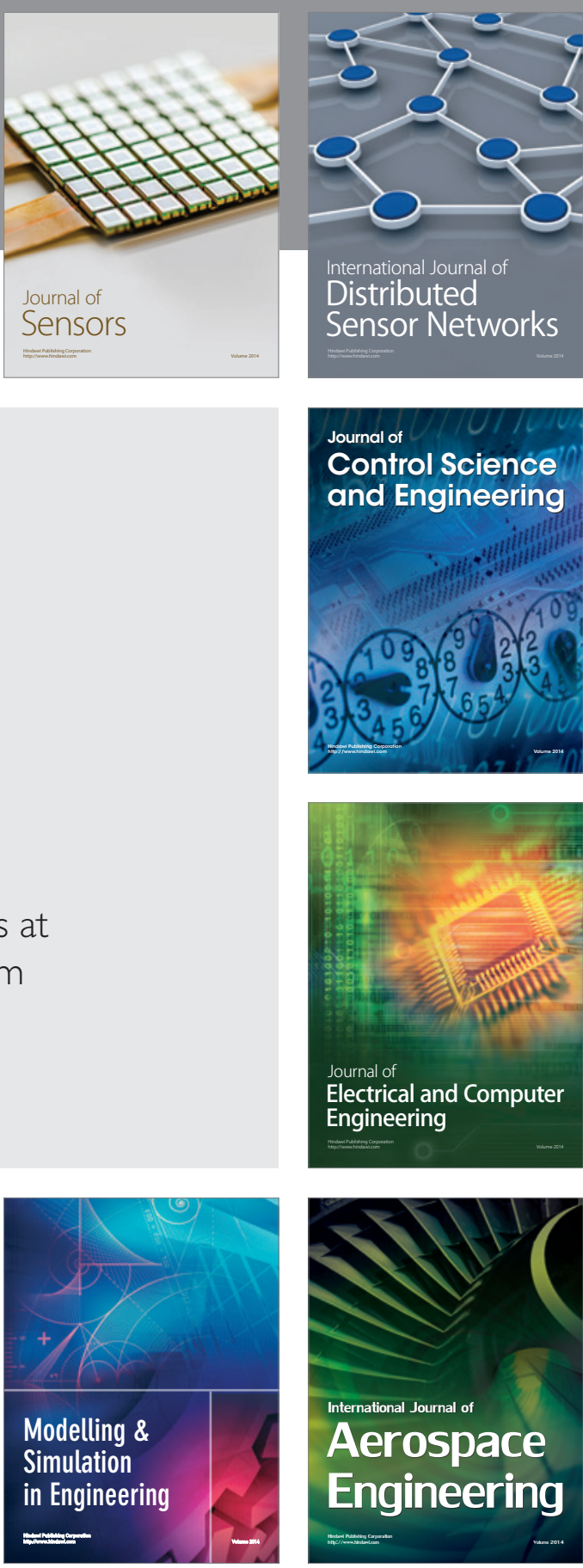

International Journal of

Distributed

Sensor Networks

Journal of

Control Science

and Engineering
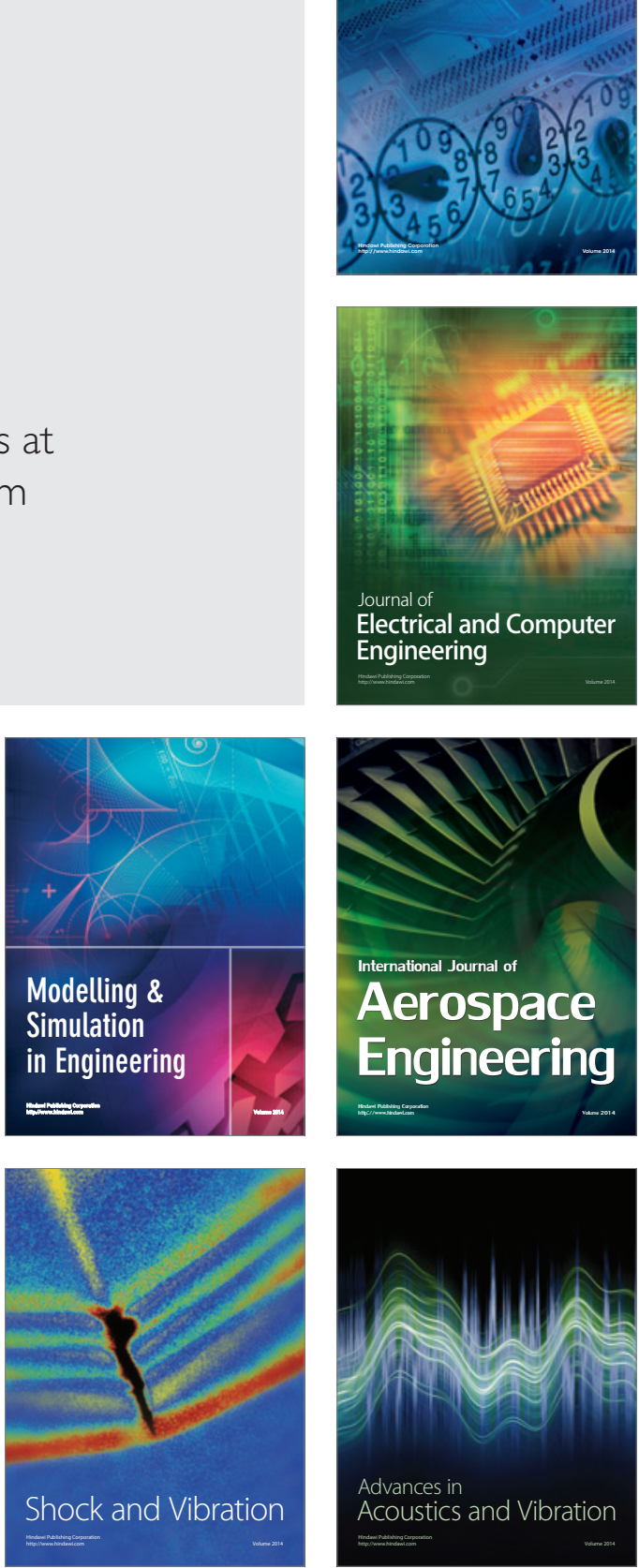